\title{
Neuronal RNA granule contains ApCPEB1, a novel cytoplasmic polyadenylation element binding protein, in Aplysia sensory
} \section{neuron}

\author{
Yeon-Su Chae ${ }^{1}$, Seung-Hee Lee', \\ Ye-Hwang Cheang ${ }^{1}$, Nuribalhae Lee ${ }^{1}$, \\ Young-Soo Rim ${ }^{1}$, Deok-Jin Jang ${ }^{1}$ \\ and Bong-Kiun Kaang ${ }^{1,2,3}$ \\ National Creative Research Initiative Center for Memory and \\ ${ }^{1}$ Department of Biological Sciences \\ ${ }^{2}$ Department of Brain and Cognitive Sciences \\ College of Natural Sciences \\ Seoul National University \\ Seoul 151-747, Korea \\ ${ }^{3}$ Corresponding author: Tel, 82-2-880-7525; \\ Fax, 82-2-884-9577; E-mail, kaang @ snu.ac.kr \\ DOI 10.3858/emm.2010.42.1.003
}

Accepted 15 September 2009

Available Online 4 November 2009

Abbreviations: 3'UTR, 3' untranslated region; CPEB, cytoplasmic polyadenylation element binding protein; EGFP, enhanced green fluorescent protein; FMRP, fragile $X$ mental retardation protein; FRAP, fluorescent recovery after photobleaching; PABP, poly (A)-binding protein; $P B$, processing body; SG, stress granule

\footnotetext{
Abstract

The cytoplasmic polyadenylation element (CPE)-binding protein (CPEB) binds to CPE containing mRNAs on their 3' untranslated regions (3'UTRs). This RNA binding protein comes out many important tasks, especially in learning and memory, by modifying the translational efficiency of target mRNAs via poly (A) tailing. Overexpressed CPEB has been reported to induce the formation of stress granules (SGs), a sort of RNA granule in mammalian cell lines. RNA granule is considered to be a potentially important factor in learning and memory. However, there is no study about RNA granule in Aplysia. To examine whether an Aplysia CPEB, ApCPEB1, forms RNA granules, we overexpressed ApCPEB1-EGFP in Aplysia sensory neurons. Consistent with the localization of mammalian CPEB, overexpressed ApCPEB1 formed granular structures, and was colocalized with RNAs and another RNA binding protein, ApCPEB, showing that ApCPEB1 positive granules are RNA-protein complexes. In addition,
}

\begin{abstract}
ApCPEB1 has a high turnover rate in RNA granules which were mobile structures. Thus, our results indicate that overexpressed ApCPEB1 is incorporated into RNA granule which is a dynamic structure in Aplysia sensory neuron. We propose that APCPEB1 granule might modulate translation, as other RNA granules do, and furthermore, influence memory.
\end{abstract}

Keywords: Aplysia; CPEB protein; fluorescence recovery after photobleaching; mRNA cleavage and polyadenylation factors; neurons; protein biosynthesis

\section{Introduction}

Posttranscriptional modification is an important mechanism for faster feedback to environmental changes in a living cell. In mammalian cell lines and yeast, dormant mRNAs are understood to form RNA granules, mainly processing bodies (P-bodies or PBs) and stress granules (SGs), which control the mRNA stability (Bashkirov et al., 1997; Anderson and Kedersha, 2002; Ingelfinger et al., 2002; van Dijk et al., 2002; Eystathioy et al., 2003). PBs are known to harbor many proteins including decapping enzymes (Dcp1, Dcp2) (Ingelfinger et al., 2002), exonuclease (Xrn-1) (Bashkirov et al., 1997) and RNA helicase (Dhh1p/ rck/p54 protein) (Fenger-Gron et al., 2005). SGs, which increase in number as cells are faced with stressful conditions such as heat, UV irradiation or heat shock (Anderson and Kedersha, 2002), consist of translation initiation factors (elF3, elF4E and elF4G) (Kedersha et al., 2002; Moon et al., 2009) and mRNA binding proteins (FMRP; fragile $X$ mental retardation proteins, CPEB) (Antar et al., 2005; Wilczynska et al., 2005). Cytoplasmic polyadenylation element binding protein (CPEB) does not merely exist in PBs and SGs, its overexpression induces the formation of $S G s$ in mammalian cells (Wilczynska et al., 2005).

The dynamics of RNA granules has attracted many biological fields, including neuroscience. In neurons, regulation of protein synthesis, especially the synapse-specific local protein synthesis, is expected to be one of the major molecular mechanisms in memory formation that is fast and economic compared to transcription modulation. The 
dynamics of proteins across the granular compound have been demonstrated by the activity-dependent change in the turnover rate of Dcp1a, a neuronal RNA granule composing protein. These neuronal RNA granules, which have been named dendritic P-body like structures (dIP-bodies), also showed unidirectional and oscillatory movement (Cougot et al., 2008). There are several reports about the functional roles of CPEB in Aplysia neurons (Si et al., 2003; Miniaci et al., 2008). Despite the rising interest in RNA granules in the neuronal cell, however, there is no report about the characterization of RNA granules and its relationship to CPEBs in Aplysia neurons. Aplysia neuron culture system is a good tool for investigating local protein synthesis. Aplysia sensory neuron can live for several days after the cell body is dissected, and the dissected neurites can produce proteins via local translation (Villareal et al., 2007), making it possible to detect the transcription-independent protein synthesis.

Here, we found that overexpressed ApCPEB1-a novel isoform of Aplysia CPEB- (a paper in preparation) in Aplysia sensory neurons had distinct foci in cytoplasm which were characterized as RNAprotein complexes. RNA granules had high rates of ApCPEB1 turnover and massive mobility in multiple directions, indicating the dynamic nature of ApCPEB1 positive RNA granules in Aplysia sensory neurons.

\section{Results}

\section{ApCPEB1 localization in cytoplasmic foci}

In mammalian cell lines, CPEB shows colocalization with RNA granules such as PBs and SGs. In particular, overexpressed CPEB induces the SG formation, which is composed of multiple proteins and RNAs (Wilczynska et al., 2005). First, we cloned a novel CPEB isoform in Aplysia, ApCPEB1 (a paper in preparation) and asked whether ApCPEB1 also forms granule-like structures in
A

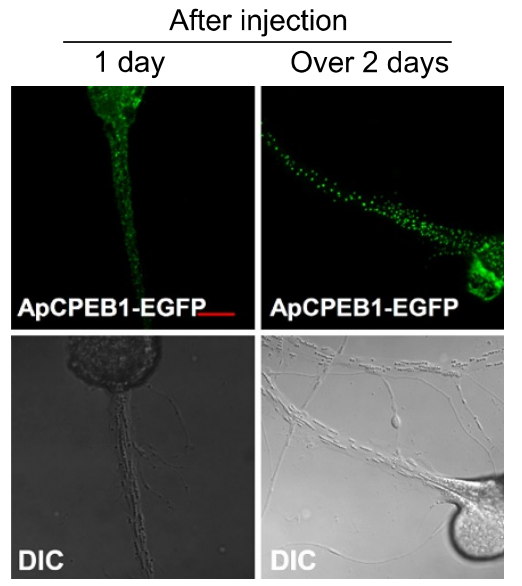

B

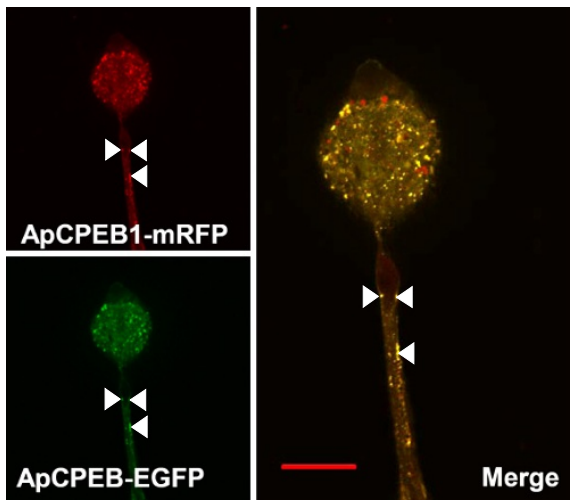

C

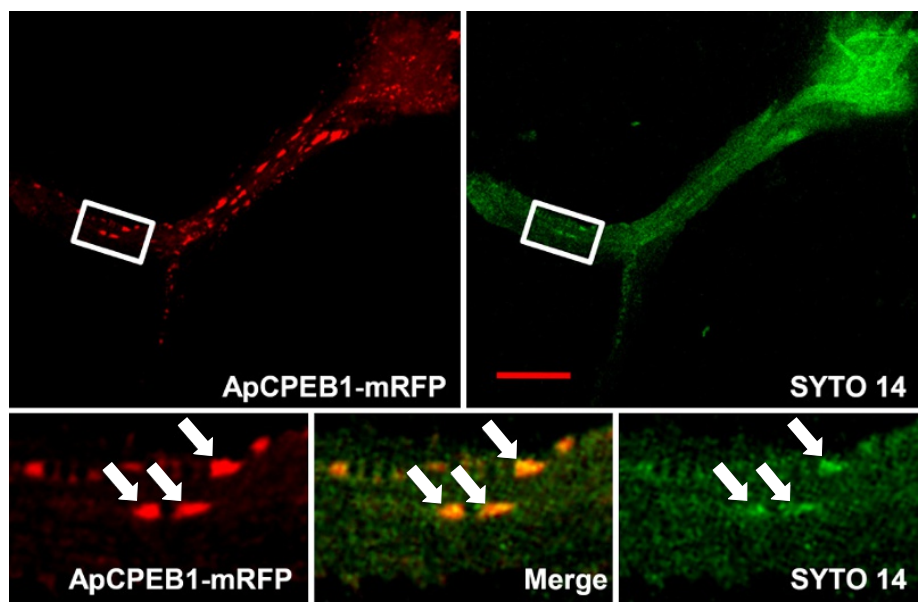

Figure 1. Colocalization of ApCPEB1 positive granules with ApCPEB and RNAs. (A) ApCPEB1 overexpression induced the granule formation. Number and size of granules are relatively small in first day after microinjection of ApCPEB1-EGFP into cultured sensory neurons. As cells were incubated over two days, the number and intensity of ApCPEB1-EGFP particles were increased. (B) ApCPEB1-mRFP was highly colocalized with ApCPEBEGFP. ApCPEB1-mRFP and ApCPEB-EGFP were coinjected into sensory cells. The arrowheads indicate colocalization between ApCPEB and ApCPEB1. (C) ApCPEB1 granule contains RNA. A RNA staining dye, SYTO 14 dye (5 $\mu \mathrm{M}$, green, Invitrogen), was treated for $30 \mathrm{~min}$ to ApCPEB1-mRFP injected live sensory neuron cultures. The arrows indicate colocalization between SYTO 14-labeled RNA granule and ApCPEB1. Scale bar, $20 \mu \mathrm{m}$. 
cultured Aplysia sensory neurons. To demonstrate the localization of ApCPEB1, we injected EGFP fused ApCPEB1 into neuronal cell body. Consistent with mammalian CPEB localization in SGs and PBs, ApCPEB1 also existed in granule-like structures in Aplysia neurons (Figure 1A). Interestingly, the number and size of ApCPEB1 positive granules increased as time passes (Figure 1A). Many cells showed cytosolic localization and few particles of ApCPEB1-EGFP on the first day after injection. After more than two days, however, many ApCPEB1 containing particles were detected. This phenomenon might have been caused by the increase of ApCPEB1-EGFP expression. Still, other possibilities, such as slow time course of incorporation of ApCPEB1-EGFP or nonspecific overexpression artifact cannot be excluded. Accordingly, ApCPEB1 overexpression can be considered as a granule inducer.

\section{ApCPEB1 foci are colocalized with ApCPEB}

In order to check whether ApCPEB1 containing granule is an ApCPEB1 self-aggregate or a multiple protein complex, we compared the localization of ApCPEB1 and that of another kind of RNA binding protein, ApCPEB, which is an Aplysia CPEB that is expected to account for different target mRNAs. If ApCPEB1 granule contains only ApCPEB1, the localization of ApCPEB would be different from that of ApCPEB1. Our results showed that, these two proteins formed cytoplasmic particles which were highly colocalized in sensory neurons (Figure 1B). Therefore, overexpressed ApCPEB1 was able to induce particles formation which also contains another form of RNA binding protein, suggesting that ApCPEB1 positive granule might be a protein complex composed of diverse proteins.

\section{ApCPEB1 positive granules contain RNAs}

RNA granules characterized in neuronal cells, such as neuronal granule or dendrite P-body like structure (dIP-body), are thought to play major roles in local protein synthesis which is one of the molecular mechanisms of memory formation. Despite the growing interest in neuronal RNA granules, there has been no report on RNA granules in Aplysia which is a good tool for studying molecular mechanisms related to translational modification.

Based on the fact that mammalian CPEB localizes in RNA granules, we performed RNA staining on ApCPEB1 overexpressed sensory neurons to determine whether ApCPEB1 particles are RNA granules or not. First, ApCPEB1 fused to mRFP was introduced into cultured sensory neurons.
SYTO 14 dye (5 $\mu \mathrm{M}$, green) was applied to live cells for RNA staining. ApCPEB1-mRFP particles were highly colocalized with SYTO 14 stained RNAs in intact sensory neurons (Figure $3 \mathrm{C}$ ), indicating that ApCPEB1 positive granules are RNA granules.

\section{ApCPEB1 has high turnover rate in RNA granules}

The dynamic exchange of RNA granule components such as TIA-1, PABP, Staufen and hDcp1a has been detected in eukaryotes (Kedersha et al., 2000; Barbee et al., 2006; Cougot et al., 2008). Our result established ApCPEB1 as an additional

\section{A}

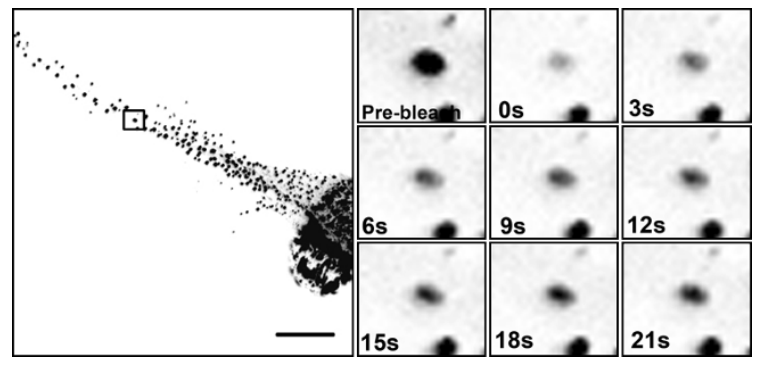

B

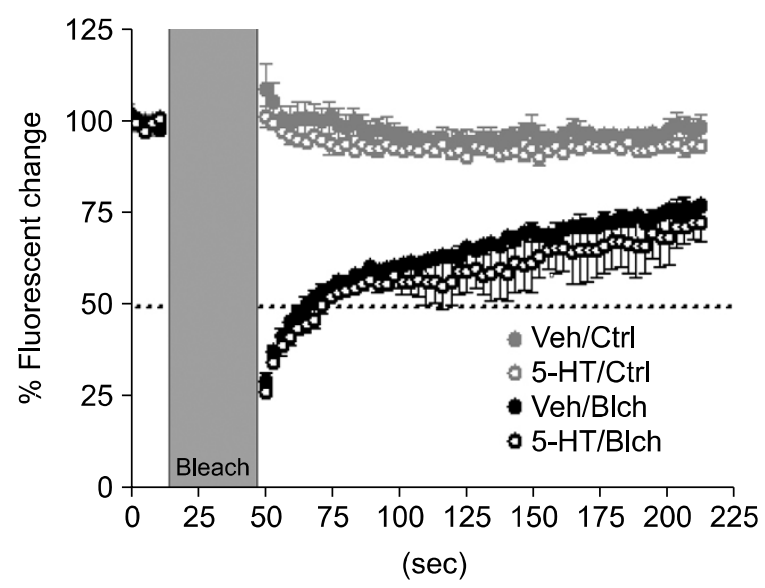

Figure 2. High turnover rates of ApCPEB1 positive granules. (A) Overexpressed ApCPEB1-EGFP particles were bleached for FRAP assay. Cultured sensory cells were injected with ApCPEB1-EGFP to form fluorescent ApCPEB1 granules. A single particle contained region was bleached after $15 \mathrm{~s}$ recording, and fluorescent signals were recorded over 10 min in every $3 \mathrm{~s}$. Image of cells with small bleached foci and enlargement of bleached regions is shown ApCPEB1 granule shows fast recovery after bleach. (B) Graph shows the recovery rates after photobleaching of 5-hydroxytryptamine (5-HT) treated $(10 \mathrm{~min}, 5 \mu \mathrm{M})$ and untreated neurons. Control means the intensity change in unbleached regions. The recovery rate was measured by the mean intensity of region of interest (ROI) and divided by intensity before bleach. Scale bar, 20 $\mu \mathrm{m}$. 
RNA granule component. Therefore, we checked ApCPEB1 exchange across RNA granules. In order to investigate the speed of ApCPEB1 turnover, fluorescent recovery after photobleach (FRAP) assay (Cougot et al., 2008) was performed in neural cells by bleaching one fluorescent granule to measure the recovery rate. We overexpressed ApCPEB1-EGFP in cultured Aplysia sensory neurons for granule formation. A single granule containing region was bleached with a high-energy laser scan of the confocal microscope. High fluorescence recovery rate of ApCPEB1-EGFP after bleaching was recorded which indicates the fast turnover rate of ApCPEB1 (Figure 2A). Subsequently, we tested the effect of 5-hydroxytryptamine $(5 \mu \mathrm{M}, 5 \mathrm{~min})$ treatment, a major neuro- transmitter in presynaptic modulation on heterosynaptic model, of ApCPEB1 turnover rate. However, no difference was detected in the recovery speed between 5-hydroxytryptamine treated and untreated groups (Figure 2A). Overall, the ApCPEB1 positive RNA granule is a very dynamic structure which has a fast turnover rate of ApCPEB1.

\section{ApCPEB1 positive RNA granule has multi directional mobility}

Next, we focused on the granular mobility. In the case of mammalian CPEB, CPEB-GFP forms cytoplasmic particles that contain $\alpha$ CaMKII mRNAs and carries the target mRNAs to distal dendrites in activity dependent manner (Huang et al., 2003).

A
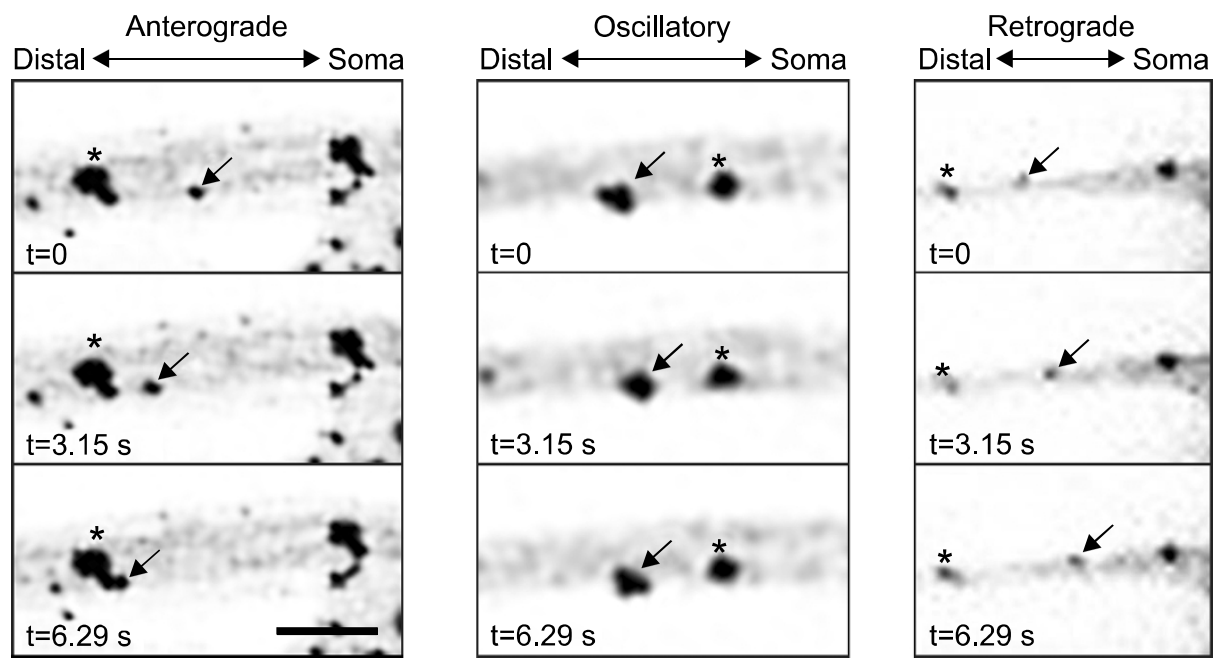

B

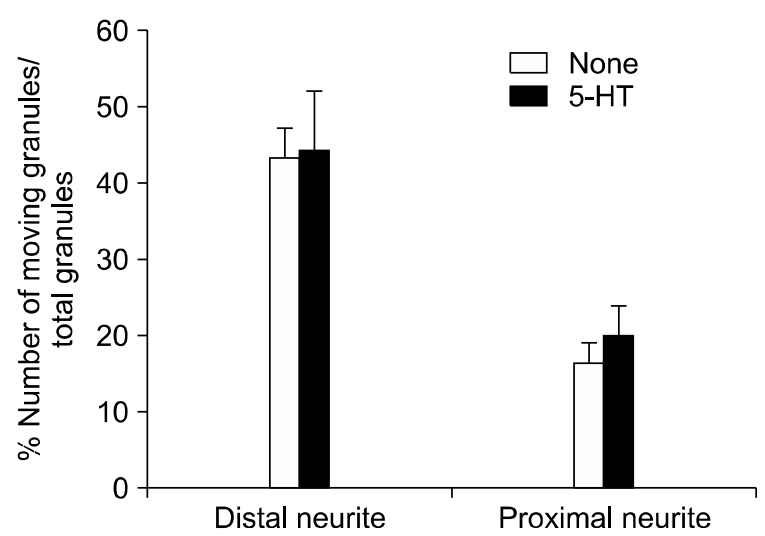

C

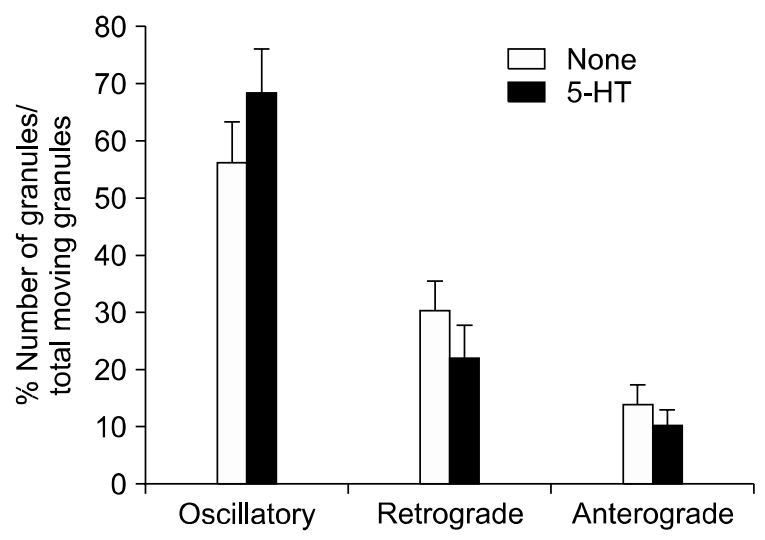

Figure 3. Characterization of mobile structures of ApCPEB1 positive granules. (A) Some ApCPEB1-EGFP particles exhibited retrograde, anterograde and oscillatory movement. *; stationary granule, arrow head; moving granule. (B) The ratio of population in moving granule per total granule was higher in distal neruites than major neurites. (C) There was difference in ratio between moving directions. The oscillatory movement showed highest percentage in total moving particles. The anterograde moving particles were the smallest group. There was significant difference between three groups. Scale bar, $5 \mu \mathrm{m}$. 
We thus checked the movement of whole ApCPEB1 containing RNA granules in cultured Aplysia cells. Real-time imaging of ApCPEB1-EGFP overexpressed sensory neurons was performed using confocal laser microscope for tracing the mobility of ApCPEB1-EGFP particles. The ratio of moving RNA granules was higher in distal neurites than in major neurites (Figure 3A, distal $43.12 \pm 3.78 \%, n$ = 8; proximal $15.97 \pm 2.84 \%, n=8 ; P<0.0001$, Student's $t$ test). On the other hand, the percentage of moving granules in 5-hydroxytryptamine treated group was almost equal to that of the untreated group (Figure 3B, distal; $44.02 \pm 7.84 \%$, proximal; $19.84 \pm 3.74 \%)$. Moreover, the direction of motile RNA granules could be categorized as unidirectional retrograde, unidirectional anterograde and oscillatory (Figure $3 A$ ). In spite of the difference in total moving ratio between distal and proximal neurites, no difference was detected in the relative ratio of each moving direction between groups (data not shown). Among the directions, however, retrograde movements were more abundant than anterograde movements, and oscillatory movement was the most common direction (Oscillatory, $56.31 \pm 6.97 \%, \quad n=8$; retrograde, $30.32 \pm 5.02 \%, \quad n=8 ; \quad$ anterograde, $13.61 \pm$ $3.48 \%, n=8)$. No difference was detected between 5-hydroxytryptamine treated and untreated groups (Figure 3C). In conclusion, ApCPEB1 containing RNA granules have multi-directional movement that is unaffected by 5-hydroxytryptamine.

\section{Discussion}

We cloned the novel Aplysia CPEB isoform, ApCPEB1, and demonstrate the existence of RNA granule in Aplysia neuron which was formed by ApCPEB1 overexpression. This is the first report about RNA granule in Aplysia neuron which suggests that it might be a functional structure. The supporting evidences are that Aplysia neuronal RNA granule is highly in common with functional mammalian RNA granule and that Aplysia RNA granule harbors ApCPEB which is a functional protein.

SGs, a sort of RNA granule, are induced not only by environmental stress (Anderson and Kedersha, 2002), but also by transfection of certain SG composing proteins including mammalian CPEB (Wilczynska et al., 2005). In the case of Aplysia, ApCPEB1 overexpression formed RNA granules that increased in number with the incubation time which in turn raised ApCPEB1 protein expression level. The increase in the number of ApCPEB1 positive granules also might be interpreted that the
ApCPEB1 incorporation into RNA granules might require times for maturation, or just as an overexpression artifact. When the case of mammalian CPEB is taken into account, however, it is more plausible that overexpressed ApCPEB1 works as RNA granule inducer in order to increase expression level. Accordingly, we can draw the conclusion that ApCPEB1 induces RNA granule formation, which is similar to the case of mammalian RNA granule.

The next evidence that exposes similar feature of Aplysia RNA granule with RNA granules in other species' is found in granule mobility. As shown in previous results, ApCPEB1 positive RNA granules were highly moving particles. The interesting feature of RNA granular mobility is the similar ratios of movement directions in mammalian RNA particles and Aplysia RNA granules. In rat hippocampal neurons, over half of the Staufen-containing transport RNPs and Dcp1-containing PBs show bidirectional movement and the other half show unidirectional movement in a similar proportion between retrograde and anterograde directions (Zeitelhofer et al., 2008). Interpretations about RNA granule mobility in neurons are mainly about the mRNA shuttling into distal dendritic regions. Transport RNPs and RNA granules are detected in neuronal cells moving in microtubule-dependent manner (Schlager and Hoogenraad, 2009), which are thought to transport mRNAs as a material of local protein synthesis (Zeitelhofer et al., 2008). The interesting part is that mammalian CPEB particles in neurons also transfer its target mRNA to distal dendrites (Huang et al., 2003). We suggest ApCPEB1 also would be a core factor in mRNA shuttling into distal part in neurons, and it might contribute for faster local translation which would be regulated in spine specific activity. Further studies about the movement of ApCPEB1 positive RNA granule might clarify its role and character.

Another common feature of Aplysia and mammalian RNA granule were demonstrated in the turnover rate of their components. The dynamics of RNA granule was studied by detecting the mobility of granules and turnover rates of components. In rat primary cultured neurons, the turnover rate of transfected GFP-hDcp1a in dIP-bodies is increased by NMDA treatment (Cougot et al., 2008). The difference in turnover rates between GFP-hDcp1a and ApCPEB1-EGFP particles was the result of unstimulated neurons. ApCPEB1, in contrast to hDcp1a, showed high recovery rate after photobleaching even in the absence of neuronal activation, suggesting that ApCPEB1 overexpression, or expression only, itself is a powerful activator of ApCPEB1 recruitment within ApCPEB1 harboring 
granules. In conclusion, this report elucidates that the RNA granules in Aplysia neuron resembles the character of that of other species.

Moreover, the colocalization of Aplysia RNA granule with a functional protein, ApCPEB, also verifies the Aplysia RNA granule as a functional unit. ApCPEB is a RNA binding protein which regulates the local translation during maintenance of long-term facilitation (LTF) (Miniaci et al., 2008). This colocalization suggests Aplysia RNA granule might play a functional role in neuron which include a memory related protein.

RNA granules in other species' are known to regulate mRNA stability which is expected to regulate local translation. There has been a report that tried to link local protein synthesis with RNA granule (Krichevsky and Kosik, 2001). Aplysia neuron culture is a generally used system in studying the relationship of LTF not only with transcription (Lee et al., 2008) but with local protein synthesis (Casadio et al., 1999; Moccia et al., 2003; Wang et al., 2009). Since local translation is a key mechanism in memory formation, linking RNA granules and synaptic plasticity with local protein synthesis might be an interesting approach. Therefore, studying the role of RNA granules in Aplysia neuron might give more insights into the approach of linking local protein synthesis and RNA granule.

\section{Methods}

\section{Cell cultures}

Primary culture of Aplysia sensory neurons was performed as described previously (Montarolo et al., 1986; Lee et al., $2001,2003)$. Briefly, central ganglia were dissected from Aplysia kurodai $(50-100 \mathrm{~g})$ and incubated at $34^{\circ} \mathrm{C}$ for $2 \mathrm{~h}$ in $1 \mathrm{Unit} / \mathrm{ml}$ protease (dispase II, Roche) dissolved in isotonic L15/ASW (1:1) media (ASW: $460 \mathrm{mM} \mathrm{NaCl}, 10 \mathrm{mM} \mathrm{KCl}$, $11 \mathrm{mM} \mathrm{CaCl}_{2}, 55 \mathrm{mM} \mathrm{MgCl}_{2}$, and $10 \mathrm{mM} \mathrm{HEPES}, \mathrm{pH}$ 7.6). After a thorough washing with ASW several times to remove residual protease, the ganglia were incubated at $18^{\circ} \mathrm{C}$ for at least $3 \mathrm{~h}$ in L15/ASW to allow recovery from heat shock. Sensory neurons were dissected from the pleural ganglia and cultured in a solution of $50 \%$ Aplysia hemolymph in isotonic L15/ASW media. Cultures were maintained in an $18^{\circ} \mathrm{C}$ incubator for 3 days to allow time for stabilization of the attachment on culture plates.

\section{DNA construction}

EGFP and mRFP was subcloned into Sall-BamHI-digested pNEX $\delta$ vector (Kaang et al., 1993) to create pNEX $\delta$-mRFP or-EGFP. A novel clone, ApCPEB1 (a paper in preparation) was obtained by performing PCR using a specific primer set. The PCR product was subcloned into HindlII-Sall site in $\mathrm{pNEX} \delta$-EGFP or -mRFP to create pNEX $\delta$-ApCPEB1EGFP or pNEX $\delta$-ApCPEB1-mRFP.

\section{Microinjection}

Cultured sensory neurons were microinjected with DNA containing injection solution in day in vitro (DIV) 3 . The injection solution for ApCPEB1 expression was made by 1 $\mu \mathrm{g} / \mu \mathrm{l}$ pNEX $\delta$-ApCPEB1-EGFP/-mRFP plasmid DNA dissoIved in TK solution and $0.1 \%$ fast green $(0.5 \mu \mathrm{g} / \mu \mathrm{l}$ pNEX $\delta$ ApCPEB-EGFP plus $0.5 \mu \mathrm{g} / \mu \mathrm{l}$ pNEX $\delta$-ApCPEB1-mRFP plasmid DNA dissolved in TK for ApCPEB-ApCPEB1 coexpression) in TK. The injection solution was loaded into filament-filled glass microelectrodes. Microinjection of DNAs into Aplysia neurons was done by air pressure as described in elsewhere (Kaang et al., 1992, 1996)

\section{SYTO 14 staining and live cell imaging}

For live-cell RNA staining, pNEX $\delta$-ApCPEB1-mRFP expressed cells was stained with $5 \mu \mathrm{M}$ SYTO 14 (Invitrogen) for 10-15 min in modified L15/ASW at room temperature and then washed twice in media before evaluation (Knowles et al., 1996). ApCPEB1 expressed cells and SYTO 14 stained culture images were acquired using a confocal laser scanning microscope (LSM510, Carl Zeiss, Jena, Germany).

The mobility of ApCPEB1-EGFP particles was measured in real-time live cell imaging. ApCPEB1-EGFP injected cultures were scanned in $3 \mathrm{~s}$ intervals, and then 5-hydroxytryptamine $(5 \mu \mathrm{M})$ was applied for 5-10 $\mathrm{min}$. The scanning after 5-hydroxytryptamine treatment was the same as before. The number of mobile granules was counted in major neurites within $100 \mu \mathrm{m}$ and in whole distal neurites (over secondary neurites which branched from major into smaller neurites). More than two distal neurites were counted in one cell, and their average was regarded as one $n$ value. The total mobility was calculated as the number of moving granules divided by total existed granules including stationary particles. The direction of movement was the number of directional moving granules per total number of mobile granules.

\section{FRAP}

For FRAP, Carl Zeiss confocal microscope was used. After ApCPEB1-EGFP microinjected sensory neurons showed fluorescent granule formation, region of interest (ROI) was placed at the most intense area of the region in which the granule resided. Five images were taken before bleach in $3 \mathrm{~s}$ intervals and then, ROI was bleached for 1000 iteration. Every $3 \mathrm{~s}$, images were acquired to trace the granule. Mean intensity was automatically traced in time scale. One non-bleached region was also traced for control.

\section{Acknowledgements}

This work was supported by the National Creative Research Initiative Program of the Korean Ministry of Science and Technology. Y.-S.C., N.L. and D.J-.J. are supported by BK21 fellowships. 


\section{References}

Anderson P, Kedersha N. Stressful initiations. J Cell Sci 2002;115:3227-34

Antar LN, Dictenberg JB, Plociniak M, Afroz R, Bassell GJ. Localization of FMRP-associated mRNA granules and requirement of microtubules for activity-dependent trafficking in hippocampal neurons. Genes Brain Behav 2005;4: 350-9

Barbee SA, Estes PS, Cziko AM, Hillebrand J, Luedeman RA, Coller JM, Johnson N, Howlett IC, Geng C, Ueda R, Brand AH, Newbury SF, Wilhelm JE, Levine RB, Nakamura A, Parker R, Ramaswami M. Staufen- and FMRP-containing neuronal RNPs are structurally and functionally related to somatic P bodies. Neuron 2006;52:997-1009

Bashkirov VI, Scherthan H, Solinger JA, Buerstedde JM, Heyer WD. A mouse cytoplasmic exoribonuclease (mXRN1p) with preference for $\mathrm{G} 4$ tetraplex substrates. J Cell Biol 1997;136:761-73

Casadio A, Martin KC, Giustetto M, Zhu H, Chen M, Bartsch $\mathrm{D}$, Bailey $\mathrm{CH}$, Kandel ER. A transient, neuron-wide form of CREB-mediated long-term facilitation can be stabilized at specific synapses by local protein synthesis. Cell 1999;99: 221-37

Cougot N, Bhattacharyya SN, Tapia-Arancibia L, Bordonne R, Filipowicz W, Bertrand E, Rage F. Dendrites of mammalian neurons contain specialized P-body-like structures that respond to neuronal activation. J Neurosci 2008;28:13793804

Eystathioy T, Jakymiw A, Chan EK, Seraphin B, Cougot N, Fritzler MJ. The GW182 protein colocalizes with mRNA degradation associated proteins $\mathrm{hDcp} 1$ and $\mathrm{hLSm} 4$ in cytoplasmic GW bodies. RNA 2003;9:1171-3

Fenger-Gron M, Fillman C, Norrild B, Lykke-Andersen J. Multiple processing body factors and the ARE binding protein TTP activate mRNA decapping. Mol Cell 2005;20:905-15

Huang YS, Carson JH, Barbarese E, Richter JD. Facilitation of dendritic mRNA transport by CPEB. Genes Dev 2003; $17: 638-53$

Ingelfinger D, Arndt-Jovin DJ, Luhrmann R, Achsel T. The human LSm1-7 proteins colocalize with the mRNA-degrading enzymes Dcp $1 / 2$ and $\mathrm{Xrnl}$ in distinct cytoplasmic foci. RNA 2002;8:1489-501

Kaang BK. Parameters influencing ectopic gene expression in Aplysia neurons. Neurosci Lett 1996;221:29-32

Kaang BK, Pfaffinger PJ, Grant SG, Kandel ER, Furukawa Y. Overexpression of an Aplysia shaker K+ channel gene modifies the electrical properties and synaptic efficacy of identified Aplysia neurons. Proc Natl Acad Sci USA 1992; 89:1133-7

Kaang BK, Kandel ER, Grant SGN. Activation of CampResponsive Genes by Stimuli That Produce Long-Term Facilitation in Aplysia Sensory Neurons. Neuron 1993;10: 427-35

Kedersha N, Cho MR, Li W, Yacono PW, Chen S, Gilks N,
Golan DE, Anderson P. Dynamic shuttling of TIA-1 accompanies the recruitment of mRNA to mammalian stress granules. J Cell Biol 2000;151:1257-68

Kedersha N, Chen S, Gilks N, Li W, Miller IJ, Stahl J, Anderson P. Evidence that ternary complex (elF2-GTPtRNA(i)(Met))-deficient preinitiation complexes are core constituents of mammalian stress granules. Mol Biol Cell 2002;13:195-210

Knowles RB, Sabry JH, Martone ME, Deerinck TJ, Ellisman $\mathrm{MH}$, Bassell GJ, Kosik KS. Translocation of RNA granules in living neurons. J Neurosci 1996;16:7812-20

Krichevsky AM, Kosik KS. Neuronal RNA granules: a link between RNA localization and stimulation-dependent translation. Neuron 2001;32:683-96

Lee JA, Kim H, Lee YS, Kaang BK. Overexpression and RNA interference of Ap-cyclic AMP-response element binding protein-2, a repressor of long-term facilitation, in Aplysia kurodai sensory-to-motor synapses. Neurosci Lett 2003; $337: 9-12$

Lee JA, Kim HK, Kim KH, Han JH, Lee YS, Lim CS, Chang DJ, Kubo T, Kaang BK. Overexpression of and RNA interference with the CCAAT enhancer-binding protein on long-term facilitation of Aplysia sensory to motor synapses. Learn Mem 2001;8:220-6

Lee YS, Bailey CH, Kandel ER, Kaang BK. Transcriptional regulation of long-term memory in the marine snail Aplysia. Mol Brain 2008;1:3

Miniaci MC, Kim JH, Puthanveettil SV, Si K, Zhu HX, Kande $\mathrm{ER}$, Bailey $\mathrm{CH}$. Sustained CPEB-dependent local protein synthesis is required to stabilize synaptic growth for persistence of long-terra facilitation in Aplysia. Neuron 2008;59:1024-1036

Moccia R, Chen D, Lyles V, Kapuya E, E Y, Kalachikov S, Spahn CM, Frank J, Kandel ER, Barad M, Martin KC. An unbiased cDNA library prepared from isolated Aplysia sensory neuron processes is enriched for cytoskeletal and translational mRNAs. J Neurosci 2003;23:9409-17

Montarolo PG, Goelet P, Castellucci VF, Morgan J, Kandel ER, Schacher S. A critical period for macromolecular synthesis in long-term heterosynaptic facilitation in Aplysia. Science 1986;234:1249-54

Moon IS, Cho SJ, Seog DH, Walikonis R. Neuronal activation increases the density of eukaryotic translation initiation factor 4E mRNA clusters in dendrites of cultured hippocampal neurons. Exp Mol Med 2009;41:601-10

Schlager MA, Hoogenraad CC. Basic mechanisms for recognition and transport of synaptic cargos. Mol Brain 2009;2:25

Si K, Giustetto M, Etkin A, Hsu R, Janisiewicz AM, Miniaci $\mathrm{MC}$, Kim JH, Zhu HX, Kandel ER. A neuronal isoform of CPEB regulates local protein synthesis and stabilizes synapsespecific long-term facilitation in Aplysia. Cell 2003;115:893904

van Dijk E, Cougot N, Meyer S, Babajko S, Wahle E, Seraphin 
B. Human Dcp2: a catalytically active mRNA decapping enzyme located in specific cytoplasmic structures. EMBO J 2002;21:6915-24

Villareal G, Li Q, Cai D, Glanzman DL. The role of rapid, local, postsynaptic protein synthesis in learning-related synaptic facilitation in Aplysia. Current Biology 2007;17:2073-2080

Wang DO, Kim SM, Zhao Y, Hwang H, Miura SK, Sossin WS Martin KC. Synapse- and Stimulus-Specific Local Translation During Long-Term Neuronal Plasticity. Science
2009;324:1536-40

Wilczynska A, Aigueperse C, Kress M, Dautry F, Weil D. The translational regulator CPEB1 provides a link between dcp1 bodies and stress granules. J Cell Sci 2005;118:981-92

Zeitelhofer M, Karra D, Macchi P, Tolino M, Thomas S, Schwarz M, Kiebler M, Dahm R. Dynamic interaction between $\mathrm{P}$-bodies and transport ribonucleoprotein particles in dendrites of mature hippocampal neurons. J Neurosci 2008;28:7555-62 